\title{
Factors Associated with Risky Sexual Behavior among Adolescents in Mbujimayi "Case of the Pupils of the School Complex of Manzonzo" (Democratic Republic of Congo)
}

\author{
Cibangu Mwana M. Wenyi Franck ${ }^{*}$, Mutombo Mutombo Albert ${ }^{2}$, Kabambi Bukasa Valentin ${ }^{1}$, \\ Tumba Kazadi Hervé1, Kabantu Mpembu Franklin², Mpunga Kanyinda John³, \\ Tshilumba Nsamba Dieudonné4, Kabeya Luboya Christophe5, Mbala Kabula Felicien6, \\ Kabunda Mbala Jhon'2, Tshibangu Kandala Justin'2, Ciamala Mukendi Paul, \\ Bukasa Tshilonda Jean Christophe ${ }^{1}$, Kazumba Nsaka Dieudonné ${ }^{7}$, Mukendi Ngeleka Lievin', \\ Cimuanga Cimuanga Nestor ${ }^{8}$, Mbulu Batatshi Valentin ${ }^{9}$, Kasuala Yambi Christophe ${ }^{10}$
}

${ }^{1}$ Higher Institute of Medical Techniques of Mbuji-Mayi, Section of Nursing Sciences, Option of Teaching and Administration in Nursing, Mbuji-Mayi, Democratic Republic of the Congo

${ }^{2}$ Higher Institute of Medical Techniques of Mbuji-Mayi, Community Health Section, Epidemiology Option, Mbujimayi, Democratic Republic of Congo

${ }^{3}$ Higher Institute of Medical Techniques of Mbuji-Mayi, Physiotherapy Section, Mbujimayi, Democratic Republic of Congo ${ }^{4}$ Nursing Department, Higher Institute of Medical Techniques of Mbuji-Mayi, Pharmaceutical Techniques Section, Mbujimayi, Democratic Republic of Congo

${ }^{5}$ Section of Nursing Sciences, Red Cross Higher Institute of Health Sciences, Mbuji-Mayi, Democratic Republic of Congo ${ }^{6}$ Higher Institute of Medical Techniques of Mbuji-Mayi, Dietetic Nutrition Section, Mbujimayi, Democratic Republic of Congo ${ }^{7}$ Higher Institute of Medical Techniques of Mbu ji-Mayi, Technical Section of the Aboratory, Option Medical Biology, Mbuji-Mayi, Democratic Republic of Congo

${ }^{8}$ Higher Institute of Medical Techniques of Mbuji-Mayi, Medical Imaging Section, Mbuji-Mayi, Democratic Republic of the Congo

${ }^{9}$ Higher Institute of Medical Techniques of Mbuji-Mayi, Water, Hygiene and Sanitation Section, Mbujimayi, Democratic Republic of Congo

${ }^{10}$ Lubumbashi Higher Institute of Medical Techniques, Nursing Science Section, Option of Teaching and Administration in Nursing, Lubumbashi, Democratic Republic of the Congo

Email: *mwanamwenyi@gmail.com

How to cite this paper: Franck, C.M.M.W., Albert, M.M., Valentin, K.B., Hervé, T.K., Franklin, K.M., John, M.K., Dieudonné, T.N., Christophe, K.L., Felicien, M.K., Jhon, K.M., Justin, T.K., Paul, C.M., Christophe, B.T.J., Dieudonné, K.N., Lievin, M.N., Nestor, C.C., Valentin, M.B. and Christophe, K.Y. (2021) Factors Associated with Risky Sexual Behavior among Adolescents in

\begin{abstract}
Unusual sexual behavior is a major problem in the life of society, both in developed and developing countries, in its magnitude. The aim of this study is to describe the factors associated with risky sexual behavior in adolescents. This is a descriptive study carried out in the town of Mbujimayi with teenage students. The following observations were made: 315 adolescent students
\end{abstract}


Mbujimayi "Case of the Pupils of the School Complex of Manzonzo" (Democratic Republic of Congo). Open Access Library Journal, 8: e7152.

https://doi.org/10.4236/oalib.1107152

Received: January 15, 2021

Accepted: March 14, 2021

Published: March 17, 2021

Copyright ( 2021 by author(s) and Scientific Research Publishing Inc. This work is licensed under the Creative Commons Attribution International License (CC BY 4.0).

http://creativecommons.org/licenses/by/4.0/ (c) (i) Open Access aged 12 to 19 responded with informed consent to our questionnaire, of which 73 reported having had their first sexual intercourse. After analyzing the data, we arrived at the following results: $23.2 \%$ had already had their first sexual intercourse; adolescents aged 12 to 14 occupied the first place with $53.4 \%$; $58.9 \%$ were men and $41.1 \%$ were women (gender ratio of 1.4 in favor of men); $23.2 \%$ had ever had sex; $64.4 \%$ of sex was done with friends; $83.6 \%$ of sexual intercourse was voluntary and $16.4 \%$ forced; $64.4 \%$ of sexual relations were the occasion of a friendly meeting; $49.3 \%$ of sexual relations were concluded on the initiative of friends; $56.2 \%$ of respondents put society as the main factor, followed by sexual pleasure with $34.2 \%$ of respondents; $79.5 \%$ of intercourse was unprotected.

\section{Subject Areas}

Nursing

\section{Keywords}

Factors, Sexual Behavior, Adolescents, Mbujimayi

\section{Introduction}

The sexual behavior of the individual reflects the values and norms acquired in his social environment and is situated in a given context. Unlike previous generations, adolescents these days have prohibitions and constraints when it comes to sexuality. Adopting pornographic sexuality exposes adolescents to specific health risks (HIV, unwanted pregnancy, etc.) [1].

In Europe, the most recent survey on the issue was carried out between 2009-2010 and the results were published in 2011. This comparative study carried out in 35 European countries and by the WHO on the sexual tendencies of pupils of 15 years old reveals that $26 \%$ of these young people had already had sexual relations.

Although there has been a decrease in early sexual intercourse in industrialized areas, the author observed an increase in sexually transmitted diseases (STDs) and found that the factors associated with risky sexual behavior were parental violence, low level of home economics, curiosity [2].

According to the WHO, there are nearly 16 million girls between the ages of 15 and 19 and about 1 million girls under the age of 15 who give birth each year. Most of these births took place in low- and middle-income countries, particularly those in sub-Saharan Africa. Each year, nearly 3 million adolescent girls aged 15 to 19 undergo unsafe abortions and $15.8 \%$ of them are living with HIV/AIDS [3].

In addition, there are different factors or situations which positively or negatively influence the sexuality of adolescents such as: the need for money to meet their daily needs, curiosity, the desire to be like friends, parents, the media, the 
lack of sex education of adolescents, communication between parents and adolescents which help to improve their level of knowledge of the risks associated with sexual activity; how to prevent sexually transmitted infections and unwanted pregnancies. But unfortunately, in the majority of African families, this subject on sexuality is still a taboo [4].

In his study in sub-Saharan Africa, Rwange [5] shows that early and risky sexual activity in French-speaking countries is intense compared to France where $7.2 \%$ of boys and $5.9 \%$ of girls are sexually active before reaching the age of 15 , of which $6.2 \%$ live with children. The predictors are under-information, low economic status of the family, curiosity, non-use of condoms, etc.

In the Situation of Adolescents and Youth in Africa report, 33\% of boys aged 15 - 19 had had multiple sexual partners in the past 12 months prior to the survey, compared to just $4 \%$ of girls in the same age group. The prevalence rate of condom using the last high-risk intercourse was 32\% for boys aged 15 - 19 and $24 \%$ for girls of the same age. The precocity of the first sexual experiences associated with the low contraceptive prevalence (condom) and/or the multi-partnership exposes adolescents to many risks including the contraction of sexually transmitted infections (HIV/AIDS), unwanted early pregnancies and the maternity, dropping out of school [6].

In Congo Brazza, Mabiala, Jr et al. (2008) [7], In their research on adolescent sexuality in Brazzaville, found that out of 900 adolescents selected by two-stage cluster sampling, one in 2 adolescents ( $\mathrm{n}=474$ including 270 girls) reported having had sex, the mean age of onset was 14.6 years and older. or less 1.7 years, early sexual intercourse (before age 14) was found in boys 39 girls (PL 0.001) multi-partnership was almost constant in boys $(81.3 \%)$ while this practice was observed in $51.1 \%$ of the girls, the risk factors for pregnancies and multi-partnership were lack of employment for the mother, dropping out of school, lack of sex education, early menarche.

In the Democratic Republic of Congo (DRC), 45 births per 1000 girls aged 15 to 19 are registered. Most are in good health, but there are still a significant number of diseases that can hamper their growth and full development. Consumption of alcohol or tobacco, unprotected sex and/or exposure to sexual violence; $18.2 \%$ of adolescents are living with HIV/AIDS [8].

In Kasai-Oriental in general, and in the town of Mbujimayi in particular, a general observation shows a large number of adolescents who run unprotected sexual risks. To this end, we deemed it appropriate to conduct a study on "factors associated with risky sexual behavior among adolescents in the city of Mbujimayi, case of the Manzonzo School group".

We asked ourselves the following questions: What is the level of sexuality of adolescents in the school group and what may be the factors associated with risky sexual behavior among adolescents in the Manzonzo school group?

We believe that curiosity, research money, mistreatment of parents, level of economy are the risk factors in Mbujimayi teens. 


\section{Material and Methods}

We opted for the questionnaire survey method supported by the structured face-to-face interview technique and documentary analysis. The target population for this study is made up of all adolescents aged 12 to 19 who responded with informed consent to our questionnaire. And our sample took into account the entire population, i.e. 315 students. We used the convenience-type non-probability sampling technique. To be part of our sample, the following conditions had to be met: To be registered in Manzonzo, voluntarily accept by free consent to participate in our study and be present on the days of the survey. We presented our results by age, sex, grade, section, condom use, type of partner, occasion, initiative, act of sex at the sexual intercourse read.

\section{Results}

The analysis of Table 1 shows that $76.8 \%$ of our respondents have not yet had their first sexual intercourse against $23.2 \%$ who have already had their first sexual intercourse.

In Table 2, we noticed that the $12-14$ age group occupies the first place in the series with $53.4 \%$, followed by that of $15-17$ years old with $24.6 \%$, against $22 \%$ of 18 - 19 years of refusal.

In light of this table, we found that $58.9 \%$ of our respondents were men, followed by $41.1 \%$ women (sex ratio 1.4 in favor of men).

It emerges from Table 2 that $42.5 \%$ of our respondents are in third place in human sciences, followed by $36.9 \%$ in $4^{\text {th }}$ in human sciences and $5.5 \%$ in $6^{\text {th }}$ in human sciences.

It emerges from Table 2 that pedagogy is the most represented section of the series with $39.7 \%$, followed by cutting and sewing with $35.6 \%, 13.7 \%$ of sales and ultimately $11 \%$ for chemistry of biology.

From Table 3, we noted that $64.4 \%$ had their first relationship with friends, followed by $24.6 \%$ with their fiancé (s) and $11 \%$ with others.

Analysis of Table 3 shows that $83.3 \%$ made their first sexual intercourse voluntarily, followed by $16.4 \%$ forced.

Table 3 explains that $64.4 \%$ of our respondents had their first sexual intercourse during a friendly meeting, followed by $24.6 \%$ of the planned outing.

Reading Table 3 revealed that $49.3 \%$ of sex was signed by friends, followed by $17.8 \%$ by both.

It emerges from Table 4 that the company is the main factor predisposing to the sexual act among our respondents with $56.2 \%$ followed by $34.2 \%$ of sexual pleasure or desire, against $4.1 \%$ of financial impossibility.

Table 1. Distribution of respondents according to first sexual intercourse.

\begin{tabular}{ccc}
\hline First report done & Effective & $\%$ \\
\hline Yes & 73 & 23.2 \\
No & 242 & 76.8 \\
Total & 315 & 100 \\
\hline
\end{tabular}


Table 2. Sociodemographic characteristics.

\begin{tabular}{cccc}
\hline Characteristics & Categories & $\mathbf{n}=\mathbf{7 3}$ & $\%$ \\
\hline \multirow{2}{*}{ Sex } & Feminine & 30 & 41.1 \\
& Male & 43 & 58.9 \\
\hline \multirow{2}{*}{ age range } & $12-14$ & 39 & 53.4 \\
& $15-17$ & 18 & 24.6 \\
& $18-19$ & 16 & 22 \\
\hline \multirow{2}{*}{ Classroom } & $3^{\text {rd }}$ & 31 & 42.5 \\
& $4^{\text {th }}$ & 27 & 36.9 \\
& $5^{\text {th }}$ & 11 & 15.1 \\
& $6^{\text {th }}$ & 4 & 5.5 \\
\hline \multirow{2}{*}{ Sections } & Biology-Chemistry & 8 & 11 \\
& Commercial & 10 & 13.7 \\
& cut and sew & 26 & 35.6 \\
\hline
\end{tabular}

Table 3. Sociodemographic characteristics.

\begin{tabular}{cccc}
\hline Characteristics & Categorys & $\mathbf{n}=\mathbf{7 3}$ & $\%$ \\
\hline Sexual partners & Friend & 47 & 64.4 \\
Reports & Fiancee & 18 & 24.6 \\
& Other & 8 & 11 \\
\hline The occasion of the & Voluntary & 61 & 83.6 \\
first sexual intercourse & Strength & 12 & 16.4 \\
\hline & Scheduled output & 18 & 24.6 \\
& Friendly meeting & 47 & 64.4 \\
& School event & 02 & 3 \\
& Other & 06 & 8 \\
\hline Report concluded on the initiative & Me & 11 & 15.1 \\
\hline
\end{tabular}

Table 4. Respondents according to the factors that motivated this first sexual encounter.

\begin{tabular}{ccc}
\hline Actors F & Effective & $\%$ \\
\hline Sexual pleasure or sexual urge & 25 & 34.2 \\
Financial impossibility & 3 & 4.1 \\
Company & 41 & 56.2 \\
Pornographic films considered & 1 & 1.4 \\
Other & 3 & 4.1 \\
Total & 73 & 100 \\
\hline
\end{tabular}

Table 5 shows that $79.5 \%$ relative to sex were not protected by a condom, against $20.5 \%$ who underlie the protection protected by a condom. 
Table 5. Distribution of respondents according to condom use.

\begin{tabular}{ccc}
\hline Use of the condom & Effective & $\%$ \\
\hline Yes & 15 & 20.5 \\
No & 58 & 79.5 \\
Total & 73 & 100 \\
\hline
\end{tabular}

\section{Discussion}

The analysis of Table 1 shows that $23.2 \%$ of our surveys have already had their first sexual intercourse. This result is superior to that found by Takou kuitche [9], which shows that $5.6 \%$ of adolescent girls have already had their first sexual intercourse.

Reading Table 2 shows that the 12 - 14 age group ranks first in the series with $53.4 \%$, followed by the 15 - 17 age group with $24.6 \%$. According to EDS (2004) [7], shows that the average age of respondents was 15 years with $56 \%$. Based on Table 2, we found that $58.9 \%$ of the adolescents surveyed were male, followed by $41.1 \%$ female. Compared to gender Takou kuitche [9] which shows that teenage girls were numerous with $64.5 \%$, against $35.5 \%$ of teenage girls.

Table 2 shows that $42.5 \%$ of our respondents are in third year of human sciences, followed by $36.9 \%$ who are in fourth year of human sciences, against $5.5 \%$ of sixth year. Our results do not agree with those of the DHS) [10], which shows that high school had an at-risk prevalence of $5.1 \%$.

Table 2 shows that education is the most represented section of the series with $39.7 \%$, followed by cutting and crimping with $35.6 \%$. According to the DHS [10], the secondary level had an HIV/AIDS prevalence of 5.1\%. In contrast, among adolescent girls with no formal education and among those with primary education, the prevalence of HIV/AIDS is almost the same at $4.3 \%$ and $4.2 \%$.

Looking at Table 3, we noticed that $64.4 \%$ had their first sexual intercourse with friends, followed by $24.6 \%$ with their fiancé (s). These results differ from those found by G. Akoa [11], which proves that his respondents had several partners with $8.2 \%$.

Analysis of Table 3 shows that $83.6 \%$ voluntarily had sex for the first time, followed by $16.4 \%$ forced sex.

Table 3 shows that $64.4 \%$ of our respondents had their first sexual intercourse during a friendly, followed by $24.6 \%$ of the scheduled outing.

Reading Table 3 shows that $49.3 \%$ of sexual relations were concluded on the initiative of friends, followed by $17.8 \%$ on the initiative of both.

The results of Table 4 prove that society is the main predisposing factor to sexual relations among our respondents with $56.2 \%$, followed by $34.2 \%$ of sexual pleasure or sexual desire. These results differ from those found by G. Akoa [11], which shows that the main factor was the mass media with $5 \% \varepsilon \xi$ o $\sigma \cup \rho \varepsilon$. In Table 5, 79.5\% of intercourse was not protected by condoms, and $20.5 \%$ was protected. These results are close to those found by Rwenge [5], for whom $40.5 \%$ of the reports of his respondents were protected and $59.5 \%$ unprotected. 


\section{Conclusions}

Our research focused on factors associated with risk for sexual behavior among adolescents in Mbuji-Mayi. In the case of the Manzonzo school group, we set ourselves the following objectives: to list all the adolescents aged 12 to 19 concerned by our study; determine the level of sexuality of adolescents; describe the factors associated with risky sexual behavior in adolescents aged 12 to 19 .

In view of the above, we have summarized our problem in these questions: What is the level of sexuality of adolescents in the Manzonzo school group and what are the factors associated with risky sexual behavior in adolescents in the Manzonzo school group?

On a sample of 315 students and by the questionnaire survey method supported by structured interview and documentary analysis, we arrived at the following results. After analyzing the data, we arrived at the following results: $23.2 \%$ of our respondents have already had their first sexual intercourse; adolescents aged 12 to 14 take first place with $53.4 \%$, followed by those aged 15 to 17 with $24.6 \%$; $58.9 \%$ of our respondents are men versus $41.1 \%$ women; $42.5 \%$ of our respondents are in $3^{\text {rd }}$ human sciences; $39.7 \%$ of respondents are in pedagogy, followed by $35.6 \%$ in cutting and sewing; $64.4 \%$ of sex was done with friends; $83.6 \%$ of sexual intercourse was voluntary and $16.4 \%$ forced; $64.4 \%$ of sexual relations were the occasion of a friendly meeting; $49.3 \%$ of sexual relations were concluded on the initiative of friends; $56.2 \%$ of respondents put society as the main factor, followed by sexual pleasure with $34.2 \%$ of respondents; $79.5 \%$ of intercourse and $25.5 \%$ were protected.

Overall, the issue of adolescents' sexual behavior includes several aspects that we believe future researchers will undertake similar research on other schools and in particular on adolescent behavior, attitude and practice regarding the issue use of condoms.

\section{Conflicts of Interest}

The authors declare no conflicts of interest regarding the publication of this paper.

\section{References}

[1] Miangotar (2010) Determinants of Premarital Sex and Adolescent Fertility in Burkina Faso. 111.

[2] WHO (2011) Report on the Global AIDS Epidemic, Updates on the AIDS Epidemic. WHO, Geneva.

[3] WHO (2014) National Report on the Development of Education in Burkina Faso.

[4] MSRG (2015) Sexual Practices of Adolescents in Schools Abidjan, Public Health.

[5] Rwange (2013) Contextual Factors of the Sexual Transmission of AIDS in Sub-Saharan Africa.

[6] UNFPA (2011) Condom Use to Prevent STIs/HIV and Unintended Pregnancy in Young Men in Sub-Saharan Africa. Lord of Seminars Botswana. 
[7] Mabiala, Jr., et al. (2008) Adolescent Sexuality in Brazzaville, Congo. Journal of Obstetric Gynecology and Reproductive Biology, 37, 510-515.

http://ww.sciencedirect.com/

https://doi.org/10.1016/j.jgyn.2007.11.033

[8] Berger, E., et al. (2010) Adults Confronted with Adolescent Sexual Behavior: Gambling Difficulties.

[9] Takoukuitche (2010) Sexuality in Schools in the City of Ouagadougou: Knowledge, Attitudes, Practices and Perceptions Linked to AIDS.

[10] DHS (2004) Premarital Sexuality and Reproductive Health of Adolescents and Young People in Sub-Saharan Africa, Paris.

[11] Akoa, G. (2012) Influence of Cultural and Economic Factors on Sexual Behaviors at Risk of HIV/AIDS among Adolescents in Burkina Faso. Institute for Demographic Research. 